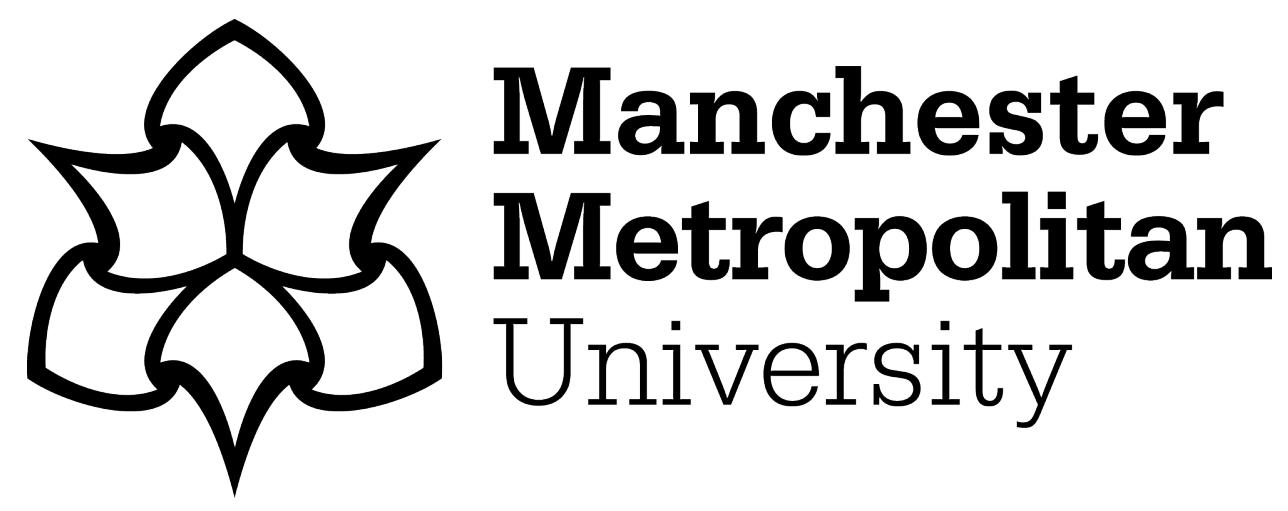

Barron, IC and Taylor, $L$ (2017) Working with the cracks in the rigging in researching early childhood professional development. Contemporary Issues in Early Childhood, 18 (1). pp. 67-79. ISSN 1463-9491

Downloaded from: https://e-space.mmu.ac.uk/759/

Version: Accepted Version

Publisher: SAGE Publications

DOI: https://doi.org/10.1177/1463949117692272

Please cite the published version 


\section{Working with the cracks in the rigging in researching early childhood professional development}

lan Barron and Lisa Taylor^ with Jan Nettleton^ \& Shabnam Amin^

*Faculty of Education, Manchester Metropolitan University

${ }^{\wedge}$ Martenscroft Nursery School and Children's Centre, Manchester

Corresponding author:

Ian Barron, Faculty of Education, Manchester Metropolitan University, 53 Bonsall Street, Manchester, M15 6GX, UK.

Email: i.barron@mmu.ac.uk

\section{Author Bios:}

lan has worked in a number of schools in London and the North of England as well as in further and higher education. A former Nursery School Headteacher, lan's doctoral research was concerned with the interconnectedness of ethnicity, family and community in children's sense of identity. His research interests are in early childhood generally, with a particular interest in professional education and training and in aspects of identity (especially gender and ethnicity).

Lisa has worked in the field of early years education for over 15 years as a class teacher, advisory teacher and is currently Deputy Headteacher and Teaching School lead at Martenscroft Nursery School and Children's Centre located in inner city Manchester. A passion is integrated education and care, recognising the holistic nature of child and family needs. Recent work has involved mentoring and working collaboratively with practitioners in a variety of early years settings to develop and embed quality practice whilst encouraging a reflective culture. She also has a particular interest in developing work with parents and carers in understanding their child's learning and the effect their contribution can make to this.

Jan has worked as an early years teacher throughout her career in schools and the private and voluntary sector. She is currently the lead teacher in the nursery class at Martenscroft Nursery School and Children's Centre. Jan is committed to involving parents and carers in their child's learning through family events, workshops and visits into the local community. In her practice, Jan seeks to build on children's motivations and interests to develop their learning both indoors and outdoors, engaging children in a rich variety of creative play opportunities.

Shabnam has spent most of her working life at Martenscroft Nursery School and Children's Centre. She has worked to support parents, shaped the learning environments and taken a lead in developing pedagogy. Shabnam has also been deployed as an Associate Trainer as part of the Department for Education funded project, Being Two, aimed at working with practitioners and parents in private and the voluntary sector early years settings to meet the needs of the most vulnerable children.

\section{Abstract}




\section{FINAL REVISED PAPER ACCEPTED BY CONTEMPORARY ISSUES IN EARLY CHILDHOOD}

This paper seeks to explore the development of the relationship between a group of early childhood academics from the same university and practitioners from a particular early years setting in the North of England into an innovative professional development and research project (2-Curious). The paper uses Foucauldian notions of heterotopia to theorise an approach to professional development and research concerned with examining the discourses and practices associated with provision for two-year-old children. In place of a transmission model of professional development and scientific preoccupations with research purity, we explore what is offered by an alternative approach that offered a broader engagement with ideas, feelings and the body and the layering of research complexity. We consider what emerges when the practitioners take the learning from the project back into their own settings and conclude by considering the possibilities and complexities of academics and practitioners working together to research and represent what emerged from the project.

\section{Key words}

Collaboration, heterotopia, professional development, research, early childhood.

\section{Introduction}

This paper seeks to explore the long standing relationship between a group of early childhood academics from the same university and practitioners from a nearby early years setting in the North of England. At its centre is a professional development programme (2-Curious) that began in 2013 as a response to the 'disadvantaged two-year-olds' agenda (Department for Education (DfE), 2011, 2013). The authors of the paper are lan, one of the academics (but not the project lead) and Lisa, the early years' setting's deputy head teacher. The paper begins with consideration of the project intentions and of the relationship of the professional development sessions, which were at its core, to the project and paper's methodological stance. In this sense, the paper is to be understood as being concerned with methodological matters (both in relation to professional development and research) as much as with theoretical provocations to review and change practice. Rather than offering a conventional literature review, followed by the findings and discussion, we then outline some of the sessions offered at the university over the course of 18 months whilst also introducing and applying notions of heterotopia (Foucault 1984, 2000, 2002, 2010). This is intended to give some sense of the ways in which the whole project has sought to ricochet between practice provocations, theoretical challenges, reflection and discussion. Another paper, which is still in development at the time of writing, considers the significance of the concept of heterotopia in engaging with discourses regarding children and childhood and also considers the remaining professional development sessions. The final part of the paper reflects upon Lisa's experiences of the project and 


\section{FINAL REVISED PAPER ACCEPTED BY CONTEMPORARY ISSUES IN EARLY CHILDHOOD}

concludes with Lisa and lan's consideration of the learning from the programme and research process and thoughts about how it might be taken forwards.

\section{The Background to the Project}

Although this paper focuses on the relationship between one academic and the deputy head teacher from one early years setting, the 2 Curious project involved other practitioners from that setting and a number of other academics from the same university. It also embraced five other early years' settings in the same part of the country, reflecting different types of provision for very young children, including a primary school with a newly established two year olds' class and a private setting. 2-Curious was led by two university-based academics (though one left part way through) and sought to design theoreticallyinformed professional development to reflect upon, question and inform existing setting-based practices as they relate to notions of children's development and behaviour. The programme was intended to enable academics and practitioners to work together to respond to the commitment expressed in the Early Years Foundation Stage (DfE, 2014:5) to give children 'the best possible start in life and the support that enables them to fulfil their potential'. It was intended to challenge the neo-liberal model of professional development concerned with ensuring compliance with policy inventions. Such approaches are predicated on notions of evidence-based practice and a belief in education as a means to economic prosperity, which as Weiner (2002: 280) notes, 'is likely to be ... over-rationalistic, seeking simple solutions to complex problems and uncertainties'.

We favoured a more provocative and reflexive approach in developing a bespoke programme of professional development, to be outlined shortly, which drew on practice-based experiences along with theoretical insights into children's development, learning and behaviours. Initially, the intention had been for this to be relatively conventional, aimed at furthering and challenging practitioners' existing understandings. This ran the risk, however, of adopting 'the traditional top-down approach - where the teacher is positioned at the bottom of the 'knowledge funnel', being handed someone else's researchbased 'best practices' to implement' (Martinovic et al, 2012:400). Such traditional models are not always well-received by practitioners and we were concerned, rather, to develop an approach which had a 'deep respect for teachers and their knowledge' (Somekh and Zeichner (2009: 10 -11). As a result, we became increasingly committed to something altogether less conventional. That it not to say, however, that we were necessarily clear about what this might be. In keeping with Henderson (2014: 274), we felt that a programme was needed that engaged with postmodernist uncertainty and conceptualised professional and academic learning as involving 'an exchange ... of flows or intensities, which connect and multiply' 


\section{FINAL REVISED PAPER ACCEPTED BY CONTEMPORARY ISSUES IN EARLY CHILDHOOD}

rather than one concerned with 'change and transformation in the humanist individualised and bounded subject'. We sought to disrupt 'modernist assumptions that knowledge is something held by experts and transmitted to docile recipients' (Lapadat, 2009: 975). The intention was that the development sessions would involve a constant toing and froing between provocations to practice, the experiences of development sessions, reflection and theoretical insights. We used an approach that 'taps the knowledge of ..... mature individuals and practising professionals with insights to share ....' (Lapadat, 2009: 975). This was seen as an on-going, interwoven and disruptive process rather than as series of development sessions that would then operate as interventions to 'improve' practice. The methodological approach adopted reflects this same fluidity and, this being the case, we have been concerned that this weaving backwards, forwards, across and between should also be a feature of the paper, rather than it following a traditional structure of literature review, methodology, presentation of findings and analysis.

\section{The Project and Notions of Research}

It seems important at the outset, therefore, to consider the relationship between the project and notions of research. The programme itself could be seen to have some of the characteristics of action research (Carr and Kemmis, 1986) since it involved the participation of academics and teachers in a project that offered provocations to reflect and act upon orthodoxies in work with young children and to consider ways of doing things differently. Certainly there are echoes of Somekh and Zeichner's (2009: 19) view of action research as 'a potent methodology for educational reform precisely because its core principle of combining action with research inevitably challenges the routines of the status quo'. Such a portrayal of the programme, however, might suggest a model of examining the effect of a particular intervention and hence something of a positivist search for progress, improvement and truth, whilst the project had a rather different methodological stance, one much more influenced by postmodernism. Following MacLure (2010: 998) we aligned ourselves with quests to 'problematize the image of the objective social scientist who thinks herself capable of producing disinterested truths and maintaining a safe distance between herself and the research participants'. Our stance is one where there are no singular truths to be found, no dispassionate or objective ways of accessing definitive knowledge, no linear journey towards enlightenment and 'the best way of doing things' based on evidence-based practice. Thus, following Holmes (2015:11), both the project and the methodological stance sought to 'have an affinity with disorder, chaos, mutation, and de-formation in an attempt to work against logic, rationality, normality, purity and science'.

Whilst positivist researchers would see any affront to research purity as opening up vulnerability to methodological challenge, critical qualitative researchers (e.g. Denzin and Lincoln, 2011) would maintain 


\section{FINAL REVISED PAPER ACCEPTED BY CONTEMPORARY ISSUES IN EARLY CHILDHOOD}

that any piece of research is likely to be messy and erratic because that is how we experience a world that defies containment. This was evident in the project when, early on, the involvement of lan, who has a senior university-based management position, was unexpectedly reduced because of other urgent priorities. These included leadership, with the head of the early years setting, of an initiative to develop a joint 'research and practice hub', bringing together provision for children and research in a proposed new building. Whilst lan's connection to 2-Curious continued as part of these plans and as a member of the setting's advisory board, it was more remote until later in the year. This has necessarily had implications for the writing of the paper, which will be discussed later.

It is not, in fact, unusual for more senior academics not to be involved directly in all aspects of data collection since these are time consuming and costly activities. Their time is usually spent, instead, on what are often seen as the more prestigious activities of analysis, conference presentation and paper writing. Middleton and Cons (2014: 284) thus argue that division of research labour 'cannot be divorced from the logics of capital'. What is unusual is to discuss this in the published paper. Significantly, Middleton and Cons (2014: 282) highlight that the presence of others 'tends to be conveniently erased in the all-important progressions from fieldwork to published ethnography'. It is hardly surprising, then, that Middleton and Cons (2014: 282) identify that 'perhaps the most notable quality of the literature on research assistants is its sparse, episodic, and ad hoc character'. Jenkins (2015: 23) highlights that there is 'a marked tendency for scholars to write out some of the methodological complexities .... for fear of disciplinary criticism.' Cons (2015: 376) warns that involving others and absence of the researcher can invite censure as possibly 'conjur(ing) questions about the (researcher's) own skills, abilities, and qualifications in the field'. Perhaps of more concern still is Cons' (2014: 376) reference to challenges to methodological purity and that by admitting that the researcher was not the only one present, or was not present at all, there is a risk of suggesting 'that our data is compromised at best, 'polluted' at worst' (Cons, 2014: 376). These concerns, however, are refuted as rooted in positivist notions about the purity of scientific method and the pursuit of supposed notions of absolute truth and fact. If we accept as critical qualitative researchers that any piece of research reflects the time, place, culture and positioning of the people involved in it, omitting to acknowledge the involvement of others means that not only is their contribution erased which is a problem ethically, their place and significance in how the events are recorded is also extinguished, making the relationship between events, their representation by particular people and analysis by others much less complex than is actually the case. These are much more significant methodological concerns than notions of scientific purity in research.

It is acknowledged that lan's distance from the project during its middle phase has posed challenges. Indeed, it has necessitated particular thought to how the paper could be written. It has involved working 
FINAL REVISED PAPER ACCEPTED BY CONTEMPORARY ISSUES IN EARLY CHILDHOOD

with the narratives and photographic records of staff from the early years setting who took part in the project in order to 'make meaning by looking back retrospectively' (Lapadat, 2009: 966). This means that the notes about the sessions have been written largely by Lisa (both contemporaneously but also subsequently), who was present and the analysis is mainly lan's. It is recognised that this decision is one that risks the charge that Lisa has been used to 'service' lan's analysis but it was one that was genuinely mutually agreed and reflected the circumstances of both lan and Lisa at that time.

This approach is also in keeping with the heterotopic stance in thinking about two year olds, professional development and the research process. In seeking to explain the idea of heterotopia, Foucault's best known example is that of the mirror. What we see in the mirror is 'real' but reflections are never the same as what they reflect. Foucault (2000: 179) explains that

'the mirror functions as a heterotopia in the sense that it makes this place that I occupy at the moment I look at my myself in the glass both utterly real ...... and utterly unreal since, to be perceived, it is obliged to go by way of the virtual point which is over there'.

The writing could thus be seen as heterotopic in that the development sessions and the words used to describe them are not intended to be simple mirror images of each other. Lord (2006:10) highlights that 'the heterotopia ..... undermines the relation between words and things, and maintains the space between them as a space. In other words, heterotopias are spaces of the difference of words and things'. Thus the concern is to open up a space between them, which serves to unsettle ready representation and explanation. It has also involved seeking to undo some of the linearity, with the project lead reading and commenting on drafts in order to support the shaping of a paper where the narratives are themselves heterotopic in that their chronology and attempts to work with meaning are both distorted and distorting. Hence the account and the whole research process can perhaps be seen as a multiply reflected and refracted version of the events they seek to represent, providing consistency with the project's conceptualisation of the development process. In other words, the professional development project, research process and the writing of papers are seen as necessarily heterotopic (disruptive of space and ways of understanding) and heterochronic (disruptive of time). As such, the narrative bears all the challenges of representing the different voices and the relationship between events at a particular point in time and later representation inherent in any research.

lan's re-involvement in the later stages of the project was partly the result of requirements relating to bidding for hub funding and the need to reflect upon the project and what was emerging from it. It also 


\section{FINAL REVISED PAPER ACCEPTED BY CONTEMPORARY ISSUES IN EARLY CHILDHOOD}

reflected, however, the commitment made early on, to work on a joint paper that would be presented initially at an international early childhood conference by both lan, the academic, and one or more members of the early years setting staff and which would subsequently be published in a journal. A key concern was that the research and practice hub should give visibility to the collaboration between the university and the practice setting. Following Carducci et al (2013: 14) this included recognition of the importance of exploring 'the various layers of power enacted both intentionally and unintentionally in research relationships and matters of representation'. We are committed, therefore, to ensuring acknowledgement of all involved and this has also meant a move away from the norms of anonymity. Such joint publication is relatively unusual and Holligan (2015: 1263) warns that 'academics routinely tend to pursue joint authorship only with those deemed to be at least as prestigious as themselves in the field'. Like Postholm (2009) and Yu (2011), we were not of the view that academic-practice collaboration meant that we all had to do everything. We decided on a division of labour that reflected necessity and our sense of our strengths.

\section{Thinking and Doing Professional Development Differently}

The concern of the development sessions was thus to unsettle and create a space between seemingly familiar early childhood experiences and the words that are used to explain them in ways that disrupt and offer alternatives to the easy convergence between notions of what it is to be two years old and the practices that are commonly held to be appropriate. The development sessions attempted to create 'that moment ... when things are not in their assigned places, when the cracks and the rigging are exposed ... when disturbed feelings won't go away, when easily living one day and then the next becomes impossible, when the present seamlessly becoming 'the future' gets entirely jammed up' (Gordon, 2011: 2).

2-Curious' eight sessions were all based at the university and took place in twilight (late afternoon / early evening) slots over 18 months. The first two sessions examined how we understood two year olds and are considered as part of another paper concerned with discourses and theories related to children and families. The focus of this paper is on the less conventional sessions that followed. These challenged dominant cognitive and psychological discourses, engaging instead, 'in homage to the important place we give sensory learning in the early years' (Dachyshyn, 2015: 39), with professional development that used touch, light, sound and the physical in seeking to understand the world, reflecting Dachyshyn's contention (2015: 39) that 'everything said, done, or felt resides in our bodies'. Following Johnson (2013: 800 ), we sought to engage in professional development which 'disturbs and unsettles wherever it sheds 


\section{FINAL REVISED PAPER ACCEPTED BY CONTEMPORARY ISSUES IN EARLY CHILDHOOD}

its light' and which acted as a provocation to established thought, practice and human subjectivities' in order to resist 'the settling of binary thinking' and to establish 'new relationships and alliances' (Johnson, 2013: 800).

\section{The Professional Development Sessions}

\section{Making friends with boxes}

The first of the less conventional sessions was led by a visitor from Norway and involved both reflection and physical activity. Lisa describes how participants were asked to use their bodies in a number of ways to keep pieces of tissue paper in the air and to discuss what was happening and what we were feeling. The group then explored cardboard boxes, first being invited to express our friendship and affection for our box, then examining its shape and feel with our eyes closed, then exploring the sounds it made when tapped, rolled, banged and thrown. This led to discussions of how adults would not normally bestow friendship or kiss on an inanimate object such as a box (though children might), opening up the space between objects and the ways in which they are usually understood. Participants also talked about how practitioners might respond if children were overly affectionate, noisy or physical in working with boxes. Play of this sort is very familiar to early childhood practitioners but the form it took in the sessions was intended to have a disturbing effect on this familiarity, to uncouple the experience from the words and justifications usually used to provide meaning and significance.

The development programme thus moved away from transmission models and was concerned to engage with postmodern uncertainty. It took account of Henderson's contention (2014: 280) that the 'intensity of being lost is necessary if we are to find our way out of the already known and into new ways of being'. Back at the early years setting, however, there was discussion about expectations of professional development. When presented with being lost, some practitioners felt they were 'not being developed' since they struggled with the necessary critical engagement with their existing beliefs and practices, with the disturbance to the relationship between practices and the words that are used to explain them. Nevertheless, the ideas were taken back into work with children. Lisa described how boxes and tubes were set up for the children in the reception area where they were used to make a boat, a train and carriages and a car with a steering wheel. Boxes, tubes, some card circles, rowing oars, a steering wheel cover and soft toy teddy bears were also set up in a large open indoor play area. The children moved inside the boxes and also rolled over and under the tubes. Subsequently, the materials and equipment were placed outside for the children to explore in a different environment. Some of the children got inside the boxes, whilst others sought to enclose soft toys in them, and also to use remote controlled cars inside 


\section{FINAL REVISED PAPER ACCEPTED BY CONTEMPORARY ISSUES IN EARLY CHILDHOOD}

them. One of the parents commented 'I always thought I had to buy expensive toys, even though the children played with the boxes the toys came in, it never occurred to me to allow the children to play with large boxes and tubes'. Another said 'I can see he is in deep thought.... l'd love to know what he was thinking in his mind'. Another commented that 'it just makes me laugh to see this photograph he's holding the box over his head and walking around - he is very interested in how things feel'. All of these comments suggest the ways in which parents as well as practitioners and academics were encouraged to see and think differently about the significance of toys, touch, feelings and everyday activities.

It was in seeking to theorise this provocation to disturb, interrupt and understand differently that we drew upon Foucault's concept of heterotopia (1984, 2000, 2002, 2010). As Wesselman (2013) notes, heterotopias are 'real' and involve enactment, practice and 'place' in contrast to 'utopias' which involve 'space' and idealised ways of being but not physical placement, presence or practice. Heterotopias have, but are not bounded by, their physical form and, in another sense, are imaginary and have a meaning beyond the place in terms of the discourses about those places, which are as important as the places themselves. In the case of the project, this led to concern to create 'real' but also imaginary spaces that brought together academics, practitioners, experiences, words, ideas, touch, sound, feeling and the physical in a process that was intended to trouble the ways in which both young children and professional development are traditionally understood. Hence Foucault (2002: xix) argues that 'heterotopias .... dessicate speech, stop words in their tracks'. This holding apart of words and spaces, of understandings about two year olds and about early years' practices and institutions, through activities and theory which disrupted the ways in which they often seep into each other, was at the heart of the development programme. We sought to work with juxtaposition ... the near and the far ...the side-by-side .... the scattered' (Foucault, 2000: 175) to disrupt common early childhood practices with other ways of understanding and experiencing.

In summary, in seeking to render extraordinary the familiarity of play with boxes in early years' settings, the group turned to Foucault's idea (2000: 179) of a heterotopia as 'a kind of contestation, both mythical and real, of the space in which we live', of the way in which we usually think about play with boxes. This contestation stems from the inadequacy of physical forms, sensation and language to represent and contain the world. The development sessions can thus be theorised as heterotopic since they sought to help practitioners and academics to look at themselves and their beliefs and every day practices but by way of extraordinary activities that created virtual points of reflection of the familiar out of the line of direct return. 
The wonder of dens

The subsequent session involved den making and was led by a drama tutor from another university. Again, den making was a common activity for many of the practitioners but the heterotopic provocation here, following Foucault (2010), was to see what different ways of making, feeling, touching, seeing and understanding in work with dens might bring about. Lisa explains how open-ended resources were used such as long rectangular shaped boards, chalks and circles. The participants worked in groups to make something, using the full space of the room. Once the construction had been made, the groups then moved around to look at and make changes to the work of other groups. This led us to think about and discuss how children must feel when others come and play with, damage or destroy what they have made. Participants were then asked to construct a den using cardboard boxes. One group created a long tunnel type of enclosure which involved crawling through the boxes.

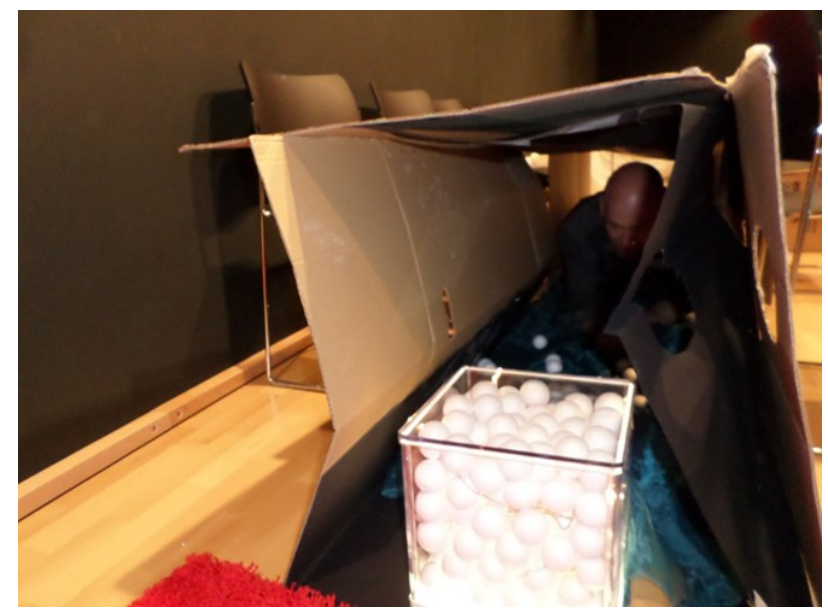

Image 1: The tunnel den under construction

Hidden bubble wrap was placed in the boxes so it made unexpected popping sounds as people crawled over the textured surface. The end was then closed off and a clear box with fairy lights was placed inside, covered with small white balls. The outside was covered by a white parachute to give different light and dark experiences as you moved from each space.

Other groups had different resources: one had blinds and bendy tubes and textured wooden square planks and a light shade; a second group had some clear umbrellas that lit up with cellophane stripes hanging down; a third had three hoops joined together to make into an igloo type den covered over with parachute material. They also used a very large parasol with lights and table-sized decorative trees. 


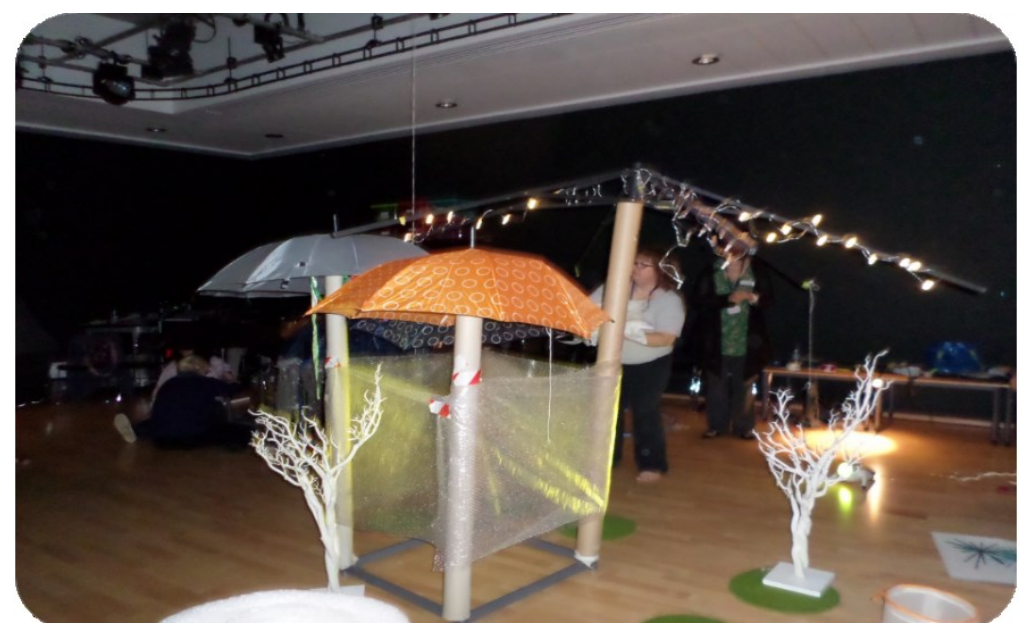

Image 2: The den with clear umbrellas that lit up

The groups then found ways of joining their dens together. The session reflects the ways in which, following MacLure (2013), the session facilitator and project lead were seeking to make room for both the golden glow and menacing shadows of wonder as alternatives and additions to words in seeking to experience and understand the world.

Thus, as the project progressed, increasing attention was paid to movement and sensation and to what theory can open up in terms of other ways of conceptualising what practice with young children might need to be about in a world where the power of words to engage with and capture its experiences, sensations and meanings is only ever insufficient. Following MacLure (2013:600), there was an interest in the way in which

'language is ... one element in a manifold of forces and intensities ..... language cannot achieve the distance and externality that would allow it to represent - i.e. to stand over, stand for and stand in for - the world'.

Instead, words constitute just one of the ways, though a dominant one, used to categorise and give meaning and significance to experience. Thus we were concerned to seek ways of 'reaching for that which escapes and exceeds language' (MacLure, 2010: 279). MacLure (2013: 228) proposes that more attention is needed to wonder, which 'is not necessarily a safe, comforting, or uncomplicatedly positive affect. It shades into curiosity, horror, fascination, disgust, and monstrosity' (Maclure, 2013: 229). Such consideration forged sessions of physical and sensory exploration and engendered a wonder that was tinged with uncomfortable feelings and troubled thoughts. 


\section{FINAL REVISED PAPER ACCEPTED BY CONTEMPORARY ISSUES IN EARLY CHILDHOOD}

The discomforts of sound

Whilst previous sessions had focused on physical, tactile and linguistic engagement, the final one was concerned with the significance of auditory experience and how this relates to how we make sense of the world around us. Lisa explained how the initial discussion focused on how listening tends to be understood as one individual human being apprehending the meaning of another, often through language. As we have seen, the adequacy of language to represent the world has already been contested by writers such as MacLure (2011) and Holmes (2015). Lisa recalls how this was then opened up into thinking about other vocal and environmental sounds as important parts of everyday sensory experience, resisting interpretation and often lacking obvious meaning.

Lisa described how participants practised some environmental listening exercises during a walk through the city. The walk took the group through a variety of contrasting environments and was conducted in silence by those taking part to avoid distraction. Participants were encouraged to focus exclusively on listening, rather than touching or looking. Lisa noted:

I could hear everyone's footsteps coming into the room and it was so silent I could sense my own breathing. We went down the steps of the building from the top right down to the bottom. I heard every sound on different textures of flooring but also sounds coming from all around. We carried on walking, crossing a busy road in two batches quickly moving along, car engines revving, a bus screeching, the speed of cars as they drove past, car horns beeping, a sound of an ambulance or a police car - I wasn't sure - I could hear the sirens but couldn't see what they were. We walked past to an underground tunnel. There was a feeling of fear, graffiti sprayed on the walls. I wasn't sure what sort of state the tunnel would be in. I felt fear yet reassurance that I wasn't alone - everyone else was with me. As we walked back, I felt I had learnt a lot about my own fears and emotions, my need to touch, make sense of sounds, distance, above, below, fear, almost mapping trying to think by looking for buildings I'm familiar with.

The walk highlighted how our listening and attention are linked, how we feel we need to understand sound, locate its origin, although sometimes we are not able to if we have never experienced it before. This caused a degree of anxiety and fear and struck us as an important point when considering the attempts and feelings of very young children as they seek to make sense of their experiences. Perhaps there are signs again of the importance of attending to light and shade in MacLure's (2013) notion of wonder (and foreboding). 
On returning to the university, Lisa recalls how themes emerged such as how participants all experienced the walk differently even though all undertook it together. Our experience and knowledge of the area affected our listening and how comfortable we felt. Several mentioned how difficult and tiring it was simply to listen, how we brought our own interests to bear, wanting to look into accommodation and shop windows along the way. We considered how this must feel for children when we encourage them to listen to something that we, rather than they, see as important. We discussed how we quickly want to give sounds a classifying and naming label, to make sense of them in neat and tidy ways and by reference to existing understandings but how the experiences may have only a stuttering relationship to the meanings attached to them. Again, the intention was to encourage academics, practitioners and children to experience everyday activities in a slightly different way with a different emphasis, to dissociate familiar experiences from the words usually used to explain them and to engage with other sensory experiences in order to explore other possibilities.

\section{Reviewing and Sustaining the Project}

The sessions were concerned, therefore, to create a 'space that eats and scrapes away at us' (Foucault, 2000:178). In common with Gonick and Hladki (2005), we were interested in exploring how we have become accustomed to making things that are so similar and so different appear to hold so much in common. We sought to do this by holding up a mirror to common early childhood practices through the development sessions, in ways that disturbed and disrupted vision, sound and feeling. Such approaches are necessary in any piece of critical qualitative research if it is to seriously engage with the problematic relationship between people, places, events, and ways in which we see, hear, feel, smell and touch them and then seek to represent them and their meanings.

Lisa highlights that the sessions provoked a range of responses from the participants. The majority of staff appeared to enjoy them, talking of 'finding the joy in working with young children again'. This is perhaps suggestive of the lack of enjoyment engendered by policy agendas and the associated regulation and raises questions about how effectively practitioners are likely to work with children in these circumstances. Some could readily see how the sessions' ideas and activities could be a provocation but also thread through into practice. Others, however, enjoyed the experiences and theoretical challenges but struggled to see how to work with them in everyday practice. The physical and active nature of the sessions challenged some people and others felt a little uncomfortable immersing themselves in the activities. Exploring why this may be the case brought up issues of feeling judged and 


\section{FINAL REVISED PAPER ACCEPTED BY CONTEMPORARY ISSUES IN EARLY CHILDHOOD}

lacking creativity. This has been a recurring theme when looking at creative approaches. Staff can love watching others lead a practical session but are reluctant to join in themselves. This in turn raises questions about the way in which feeling judged and inadequate might impact upon developing a reflective culture. Making a difference to how we think and practice seemed to require the creation of discomfort, reflexivity and a receptiveness to working with theory. This leads to questions about what supporting structures and spaces would support those feeling discomfort and allow for a culture of reflection and disturbance of the taken for granted and what existing structures need to be challenged?

As the practitioners took the learning back into the settings, questions suggested themselves about how what happened in one context with a group of reasonably like-minded practitioners, researchers and academics might translate into practice with other practitioners who had not necessarily signed up to the professional development journey and certainly had not been on it as part of the project group. As a 'teaching school', seeking to improve practice elsewhere, the early years setting is concerned to use the project as a spur to work with practitioners in other settings, which is all the more challenging when these other settings need to improve 'quality' as defined and regulated by government. This was difficult enough in the project group and we are still some way from thinking through how to take this forwards on a larger scale. All of this raises interesting considerations for strategic leaders about whether the learning from the 2-Curious project necessitates looking differently at common forms of professional development, which often reflect policy initiatives and transmission models.

In terms of the project's success in encouraging academics and practitioners to work together, there is much that is positive. Overall, however, our sense is that academic colleagues did not enter sufficiently into practitioner settings to understand fully the set of understandings that commonly circulate and give meaning to work with young children and how these bump against policy discourses and regulatory requirements. There were also too few opportunities for practitioners to engage in this troubling of assumptions with university staff or to discuss the impact of the sessions on their thinking and practice, restricting the scope to engage with established ways of seeing, thinking, narrating and acting. The project needs to continue to foster the 'growth of capabilities to resist and transgress systems that cast power relations and historical events as fixed and necessary' (Lord, 2006:2) but we struggled to find sufficient space for such discussions, which are seen as important in challenging and making disciplinary mechanisms falter. Finding such space will be significant in taking the project forwards to its next stage. 
This brings us to consideration of the learning from the research and the professional development programme. lan's distance from the majority of the development sessions but involvement in other aspects of the setting raises a number of issues. Membership of the early years' setting's advisory board has led to lan having greater familiarity with government expectations of the setting's outcomes for work with children and families than is often the case for researchers, adding richness to working with the meanings that were operating. Methodologically it could be seen as problematic, however, since the distance from other aspects of work with the setting has led to a complex relationship to the project, with the other author of the paper and to the paper that has emerged. It has led to the need for the early years setting staff to reconstruct and re-story their experiences and to a multiple layering as lan offered insights on those reconstructions and Lisa responded to lan's further re-storying. In drafting the paper, we also attempted to interrupt easy linearity in order to reflect something of the way in which the professional development sessions and research methods sought to prise apart ready ways of understanding. This approach is very consistent with the heterotopic theoretical stance of the paper but has proved to be very difficult to do whilst also making the organisation of the paper accessible. This has meant returning the paper to a more conventional structure, though one in which there is no separate review of literature, with the theory rather being interwoven as it was used as provocation in the development sessions.

We do feel that both the university and the early years setting have benefitted by taking part in aspects of professional development, analysis of the process, preparation for and presentation at a conference and the production of a paper. We will continue our discussions about how to develop our collaboration in all aspects of research and professional development processes, bearing in mind our commitment to opening up a space between activities and the words used to describe and explain them as part of the process of writing and analysis, our concern to make the collaboration mutually beneficial rather than exploitative, the constraints of our roles, and our belief in the importance of playing to our strengths. We trust that these matters and their theorisation offer something of interest to others.

\section{Acknowledgements}

I would like to thank the project lead, Rachel, and the anonymous reviewers, for invaluable comments on drafts of this paper.

\section{References}

Carducci R, Pasque PA, Kuntz AM, \& Contreras McGavin M (2013) Disrupting façades of clarity in the teaching and learning of qualitative research. Qualitative Research in Education, 2 (1): 1-26 
Carr W \& Kemmis S (1986) Becoming critical: education, knowledge and action research. London: Falmer

Cons J (2014) Field dependencies: mediation, addiction and anxious fieldwork at the India-Bangladesh border. Ethnography 15 (3): 375-93

Dachyshyn DM (2015) Being mindful, heartful, and ecological in early years care and education. Contemporary Issues in Early Childhood, 16(1): 32-41

Denzin N \& Lincoln Y (2011) The SAGE handbook of qualitative research. London: Sage

Department for Education (2011) Supporting Families in the Foundation Years. London: Crown Copyright.

Department for Education (2013) More Great Childcare: Raising quality and giving parents more choice. London: Crown Copyright.

Department for Education (2014) Statutory framework for the early years foundation stage. London: Crown Copyright.

Foucault M (1984) Of Other Spaces: Utopias and Heterotopias. Architecture /Mouvement/ Continuité, October 1984 ('Des Espace Autres', March 1967) Translated from the French by Jay Miskowiec)

Foucault M (1998) The Will to Knowledge: The History of Sexuality 1. London: Penguin.

Foucault M (2000) Aesthetics: Essential Works, volume 2. London: Penguin.

Foucault M (2002) Power. Essential Works, volume 3. London: Penguin.

Foucault M (2002) The Order of Things: An archeology of the human sciences. London: Routledge Classics.

Foucault M (2010) Les Corps Utopique, Les Hétérotopies. Clamercy: Éditions Lignes.

Gonick M \& Hladki J (2005) Who are the participants? Rethinking representational practices and writing with heterotopic possibility in qualitative inquiry. International Journal of Qualitative Studies in Education 18(3): 285-304.

Gordon A (2011) Some Thoughts on Haunting and Futurity. Borderlands,10(2): 1-21.

Henderson L (2014) Teacher Learning in the In-between: encountering an 'invisible barrier' Contemporary Issues in Early Childhood 15 (3): 272-283

Holligan C (2015) Becoming a researcher: forms of capital associated with "research capacity" trajectories of young British social anthropologists. International Journal of Qualitative Studies in Education 28 (10): 1249-1270

Holmes, R. (2015) My tongue on your theory: the bittersweet reminder of every-thing unnameable. Discourse: Studies in the Cultural Politics of Education 37(5): 1-17 
Jenkins SA (2015) Assistants, guides, collaborators, friends: the concealed figures of conflict research. Journal of Contemporary Ethnography 0891241615619993, first published on December 18, 2015

Johnson P (2013) The geographies of heterotopia. Geography Compass 7(11): 790-803.

Lapadat JC (2009) Writing our way into shared understanding collaborative autobiographical writing in the qualitative methods class. Qualitative Inquiry 15 (6): 955-979

Lord B (2006) Foucault's museum: difference, representation, and genealogy. Museum and Society 4(1): $1-14$.

MacLure M (2010) The offence of theory. Journal of Education Policy 25 (2): 277-286

MacLure M (2011) Qualitative inquiry: where are the ruins? Qualitative Inquiry 17(10) 997-1005

MacLure M (2013) The Wonder of Data. Cultural Studies $\leftrightarrow$ Critical Methodologies 13(4) 228-232

Martinovic M, Wiebe N, Ratkovic S, Willard-Holt C, Spencer T \& Cantalini-Williams M (2012) 'Doing research was inspiring': building a research community with teachers. Educational Action Research $20: 3,385-406$

Middleton T and Cons J (2014). Coming to terms: reinserting research assistants into ethnography's past and present. Ethnography 15 (3): 279-90.

Postholm MB (2009) Research and development work: developing teachers as researchers or just teachers? Educational Action Research 17 (4): 551-565

Postholm MB \& Skrøvset S (2013) The researcher reflecting on her own role during action research. Educational Action Research 21(4): 506-518

Somekh B \& Zeichner K (2009) Action research for educational reform: remodelling action research theories and practices in local contexts. Educational Action Research 17 (1): 5-21

Weiner G (2002) Uniquely Similar or Similarly Unique? Education and development of teachers in Europe, Teaching Education 13 (3): 273-288

Wesselman D (2013) The high line, "The Balloon," and heterotopia. Space and Culture 16(1): 16-27

Yu K (2011) Exploring the nature of the researcher-practitioner relationship in qualitative educational research publications. International Journal of Qualitative Studies in Education 24 (7): 785-804 